\title{
Uma Proposta de Modelo Metacognitivo de Aquisição da Escrita no Ensino Universitário Moçambicano
}

\section{A Proposed Metacognitive Model for Writing Acquisition in the Mozambican University Teaching}

\section{Un modelo metacognitivo propuesto para la adquisición de la escritura en el Docencia universitaria de Mozambique}

\author{
iD Nelson Maurício Ernesto \\ Universidade de Cape Town (UCT), Rondebosch, Cape Town, África do Sul. \\ E-mail: nelernest@yahoo.com.br.
}

\begin{abstract}
Resumo: A metacognição sempre esteve presente nos modelos processuais de produção escrita (ROHMAN, 1965 FLOWER; HAYES, 1980 BEREITER; SCARDAMALIA, 1987), com destaque à presença de estratégias de aprendizagens (metacognitivas) que auxiliam a produção textual, através de uma frequente monitorização e autorregulação da cognição na produção textual. Este artigo propõe um modelo metacognitivo de tratamento da escrita, tomando em consideração que a aprendizagem da escrita também circunscreve-se ao ensino universitário, assumindo também que um ótimo produtor de escrita é o que faz uso das estratégias metacognitivas no desenvolvimento da produção escrita, o que não é operado pelo produtor de escrita menos eficiente.
\end{abstract}

Palavras-chave: Metacognição. Estratégias metacognitivas. Fases do processo de escrita. Modelo metacognitivo de ensino.

Abstract: Metacognition has always been present in procedural models of written production (ROHMAN, 1965 FOWER; HAYES, 1980 BEREITER; 
SCARDAMALIA, 1987), with emphasis on the presence of learning strategies (metacognitive) that help textual production, through frequent monitoring and self-regulation of cognition in textual production. This research proposes a metacognitive model to address text production, taking into account that the learning of writing is also limited to university teaching and assuming that a great producer of writing is the one who makes use of metacognitive strategies in the development of written production, which is not operated by the less efficient writing producer.

Keywords: Metacognition. Metacognitive strategies. Stages of the writing process. Metacognitive teaching model.

Resumen: La metacognición siempre ha estado presente en los modelos procedimentales de producción escrita (ROHMAN, 1965 FLOWER; HAYES, 1980 BEREITER; SCARDAMALIA, 1987), con énfasis en la presencia de estrategias de aprendizaje (metacognitivas) que ayudan a la producción textual, a través de Seguimiento frecuente y autorregulación de la cognición en la producción textual. Esta investigación propone un modelo metacognitivo de tratamiento de la escritura, teniendo en cuenta que el aprendizaje de la escritura se limita también a la docencia universitaria y asumiendo que un gran productor de escritura es quien hace uso de estrategias metacognitivas en el desarrollo de la producción escrita, que no se opera. por el productor de escritura menos eficiente.

Palabras-clave: Metacognición. Estrategias metacognitivas. Etapas del proceso de escritura. Modelo de enseñanza metacognitivo.

Submetido em 23 de setembro de 2020.

Aceito em 09 de fevereiro de 2021.

Publicado em 08 de dezembro de 2021. 
Uma Proposta de Modelo Metacognitivo de Aquisição da Escrita no Ensino Universitário... Nelson Maurício Ernesto

\section{Introdução}

O conceito de metacognição foi, na década de 70 , proposto por John Flavell, investigador pioneiro deste domínio científico e, no âmbito da teoria psicológica de processamento de informação, diz respeito à cognição sobre a cognição ou o pensar sobre o pensar. Entre a metacognição e a cognição parece não haver uma distinção hierárquica, porque os fenômenos atinentes à metacognição resultam de processos cognitivos e, por consequência, a metacognição é mais um fenômeno da cognição e não um fenômeno acima da cognição.

A metacognição envolve duas áreas que se intercetam no decurso do processo cognitivo: monitorização e regulação da cognição. De uma forma geral, o primeiro processo permite um frequente acompanhamento do processo cognitivo, enquanto o segundo permite um constante ajuste do processo cognitivo.

No sistema educativo, esse conceito alude ao processamento da informação que foi sujeita à aprendizagem, procurando avançar formas de melhorar o desempenho de alunos com dificuldades de aprendizagem em diferentes áreas do conhecimento como, por exemplo, a leitura e a escrita. Assim, o mesmo ocorre quando aplicado à aprendizagem escolar (incluindo a aprendizagem de Língua Segunda), quando procura defender o uso de mecanismos cognitivos que permitem monitorizar e autorregular a aprendizagem em tempo real.

A consciencialização (ou monitorização) e controle do processo cognitivo no decurso da aprendizagem ocorrem quando o aluno está a aplicar estratégias de aprendizagem que, segundo Oxford (1990, p. 8), correspondem a "ações específicas realizadas pelo aluno para tornar a aprendizagem mais fácil, rápida, mais agradável, mais autodirigida, mais eficaz e mais fácil de transferir para novas situações". Ou seja, as estratégias de aprendizagem representam um conjunto de capacidades mentais que direcionam a aprendi- 
Uma Proposta de Modelo Metacognitivo de Aquisição da Escrita no Ensino Universitário... Nelson Maurício Ernesto

zagem, tornando-a mais efetiva e com a possibilidade de $o$ aluno transferir essa aprendizagem para novos contextos.

Essas estratégias podem ser cognitivas, ligadas à tarefa de aprendizagem; metacognitivas, que permitem um constante controle da adequação da informação de aprendizagem; afetivas e sociais, que aludem ao afeto e apelam a uma aprendizagem cooperativa na sala de aula. No entanto, apesar de terem de operar em conjunto, as que mais se salientam são as metacognitivas, por desencadearem monitorização e autorregulação da aprendizagem.

A aprendizagem da escrita é complexa e opera-se ao longo de toda a vida escolar. As causas que conduzem a essa complexidade e morosidade na aquisição da escrita decorrem, entre outros aspetos, de a escrita envolver uma representação cognitiva de letras e palavras, dos conteúdos a comunicar, e, por fim, de a escrita requerer uma planificação e estruturação da mensagem que se pretende comunicar.

No caso de Moçambique, há que notar que a Língua Portuguesa é usada pela maioria da população como uma Língua Segunda, pois, antes de aprenderem este sistema linguístico, usam as suas línguas maternas, constituídas pelas Línguas Bantu. Por outro lado, há evidências de, em contexto universitário, os estudantes revelarem erros de escrita, ao nível da ortografia e acentuação, conforme descrito em estudos de diversos autores (SIOPA et al., 2003 ERNESTO, 2006 GONÇALVES; VICENTE, 2010; SIOPA, 2015).

Nessa ordem de ideias, neste artigo, avança-se uma proposta de ensino de estratégias de aprendizagem que deverão propiciar a aquisição da escrita em estudantes que usam a Língua Portuguesa (LP) como Língua Segunda (LS). Na esteira desta proposta, está a assunção de que um ótimo produtor de escrita é o que faz uso das estratégias de aprendizagem no desenvolvimento da produção escrita, o que não é operado pelo produtor de escrita menos eficiente. 
Uma Proposta de Modelo Metacognitivo de Aquisição da Escrita no Ensino Universitário... Nelson Maurício Ernesto

\section{A escrita: ortografia e acentuação}

Na visão de Rebelo e Fonseca (2001, p. 34), "quando referimos apenas à ortografia visamos considerar a escrita em termos de codificação da linguagem, isto é, nos caracteres gráficos manuais ou impressos que reproduzem corretamente as palavras, os acentos [...]". Ou seja, a noção de ortografia, que é um construto social, porque para escrever corretamente deve-se obedecer a uma convenção socialmente partilhada, congrega, de forma explícita, a área da acentuação. Por essa razão, o domínio das regras ortográficas implica, necessária e inclusivamente, o domínio das regras de acentuação (HORTA; ALVES, 2004 REBELO; FONSECA, 2001).

Os diferentes estudiosos das questões relativas à ortografia (HORTA; ALVES, 2004 REBELO; FONSECA, 2001 MORAIS; TEBEROSKY, 1994) consideram, de um modo geral, que esta, que como vimos também inclui o conhecimento das regras de acentuação gráfica, é um dos elementos constitutivos da produção textual. Consequentemente, a aprendizagem da ortografia, nesse sentido, envolverá a aprendizagem da produção escrita em geral, porque a ortografia é um elemento indissociável do processo de produção escrita. Por isso, esse posicionamento não invalida a aprendizagem de grafar de forma acertada as palavras no texto, ou seja, "não se conclua daqui que aprender a executar bem as letras até ao nível de fazê-las como que automaticamente é tarefa de somenos importância e descuidar no ensino [...]" da produção escrita (REBELO; FONSECA, 2001, p. 35).

Na procura de explicitação das etapas por meio das quais se passa na aquisição da escrita, vários autores (KARMILOFF-SMITH, 1992 GRAHAM; HARRIS, 2000) lançaram hipóteses sobre as diversas fases de aquisição da produção escrita. No entanto, e tomando como base Rebelo e Fonseca (2001), é possível segmentar as fases de aquisição da produção escrita, fundamentalmente, em duas: (i) escrita elementar e (i) escrita avançada. 
Uma Proposta de Modelo Metacognitivo de Aquisição da Escrita no Ensino Universitário... Nelson Maurício Ernesto

A escrita elementar envolve a aprendizagem da competência fonológica (relação fonema/grafema), disposição dos grafemas na palavra, a velocidade de escrita e a escrita de palavra com recurso à memória, o que impõe a ausência de padrão de palavras que se possa recorrer e reproduzir. A escrita avançada abarca a aprendizagem da ordenação das palavras na frase e no texto, incluindo-se o uso de regras gramaticais bem como de acentuação e pontuação. Trata-se, por conseguinte, da aprendizagem de uma escrita de maior complexidade relativamente à aprendizagem da escrita elementar.

Nesta ordem de ideias, a escrita elementar é aprendida nos primeiros anos de escolaridade (Ensino Primário do $1^{\circ}$ e $2^{\circ}$ graus), enquanto a escrita avançada é aprendida nos níveis de escolaridade subsequentes, Ensino Secundário e Ensino Pré-Universitário. Considera-se, contudo, que a aprendizagem da escrita avançada não se opera apenas nestes níveis de escolaridade, posto que ela pode ocorrer até ao nível do Ensino Universitário, ou seja, "a aprendizagem da escrita avançada [...] não restringe à escolaridade obrigatória nem se pode considerar circunscrita ao período de aprendizagem escolar, mesmo que esta seja de nível superior ou universitário" (REBELO; FONSECA, 2001, p. 35).

Em Moçambique, os estudos sobre a escrita incidem sobre 0 contexto universitário, denunciando problemas no componente ortográfico como elemento impeditivo de produção textual. SIOPA et al. (2003, p. 2) analisam "um corpus-amostragem de aproximadamente 7900 palavras, composto por textos escritos produzidos por 12 estudantes das licenciaturas na área da língua portuguesa" em que descreveram, entre outras, a área dos Traços Formais1, destacando-se "erros" de ortografia, com 44 casos, cerca de 15,5\% do corpus-amostragem; "erros" de acentuação, totalizando 40 ocorrências equivalentes a $14,1 \%$ da totalidade dos "erros" isolados. Gonçalves e Vicente (2005) estabeleceram uma tipologia de Desvios Formais, reagrupando e reclassificando a tipologia de Des-

1 Traços Formais, assim como Desvios Formais, são termos usados para referir a casos de "erros" de ortografia e acentuação, assumindo que tanto o primeiro como a segundo "se estabelecem segundo uma convenção oficial para a representação dos sons da fala, sujeita a revisões periódicas, nem sempre pacíficas" (SIOPA et. al, 2003, p. 6). 
Uma Proposta de Modelo Metacognitivo de Aquisição da Escrita no Ensino Universitário... Nelson Maurício Ernesto

vios Formais isolada no estudo de Siopa et al. (2003). Para o efeito, esses autores elevaram o corpus-amostragem de textos escritos para cerca de 23500 palavras (30 estudantes), o que equivale a cerca de $75 \%$ do universo de textos produzidos pelos estudantes universitários (cerca de 31000 palavras).

Ernesto (2006) realizou uma pesquisa com um corpus de textos produzidos por 60 estudantes universitários, que permitiram constituir uma amostra com cerca de 31000 palavras. No isolamento dos Desvios Formais, o estudo apoiou-se na tipologia proposta por Gonçalves e Vicente (2005) que, como atrás se referiu, é um refinamento de uma investigação pioneira nesta área em Moçambique que fora apresentada por Siopa et al (2003), mas com dados do ensino secundário em Moçambique. Gonçalves e Vicente (2010) recuperam a tipologia de "erros" sobre os Desvios Formais no seu estudo realizado cinco anos atrás. Siopa (2015) retoma o estudo sobre "erros" produzidos por estudantes universitários e, além de analisar áreas como a gramática e o discurso, presta também atenção a "erros" sobre Desvios Formais, incidindo sobre a ortografia e acentuação. Nessa pesquisa, a autora apoia-se em textos escritos de cerca de 20 estudantes, dos 31 inicialmente fixados para o estudo.

Conforme se pôde verificar, a ocorrência de "erros" de ortografia e de acentuação em textos escritos de estudantes universitários moçambicanos é uma problemática que tem servido de base para a produção de diferentes pesquisas, procurando avançar propostas para a sua redução progressiva nas produções escritas dos pupilos.

$\mathrm{O}$ artigo que ora se apresenta visa inclusivamente isso, ou seja, com base numa proposta de modelo metacognitivo de aquisição da escrita, sobretudo na área dos Desvios Formais, ver paulatinamente reduzidas as ocorrências de "erros" de ortografia e acentuação, entre os estudantes do ensino universitário moçambicano. 
Uma Proposta de Modelo Metacognitivo de Aquisição da Escrita no Ensino Universitário... Nelson Maurício Ernesto

\section{Abordagem metacognitiva de produção escrita}

A partir dos anos 1980, a metacognição começou a procurar explicações em relação à organização do processamento da informação na produção escrita e suas implicações para o processo de ensino-aprendizagem. Por conseguinte, surgiram pesquisas emblemáticas (FLOWER; HAYES, 1980 BEREITER; SCARDAMALIA, 1987) as quais procuravam relacionar a abordagem metacognitiva de produção escrita e o seu ensino-aprendizagem. Essas pesquisas procuraram mostrar a necessidade de a produção escrita incidir mais sobre a compreensão do processo e não propriamente sobre o produto. Para o efeito, os estudos em causa salientam e explicitam as diferenças entre os processos de escrita de produtores avançados e produtores principiantes (SITKO, 1998).

As pesquisas acerca da produção escrita seguiram, de uma forma geral, os princípios lógicos orientadores de metacognição, propostos inicialmente por John Flavell nos anos 70 e reelaborados por outros autores (BROWN, 1987 BAKER; BROWN, 1984 CROSS; PARIS, 1988). Essas reelaborações destacam a necessidade de se ter o conhecimento da tarefa de produção escrita, disponibilização de fontes cognitivas para a realização da tarefa, monitorização e autorregulação do processo cognitivo envolvido na realização da tarefa.

Nessa perspetiva, considera-se que, na produção escrita, estão presentes dispositivos cognitivos que permitem uma coordenação desse processo. Em Flower e Hayes (1980), considera-se que o dispositivo cognitivo que monitoriza e autorregula o processo de produção escrita é o "monitor", enquanto em Bereiter e Scardamalia (1987) defende-se a existência de "controlador executivo", que se responsabiliza pela verificação do desenvolvimento do processo de produção escrita (monitorização e autorregulação).

Os modelos do processo de produção escrita apresentados por esses autores (FLOWER; HAYES, 1980; BEREITER; SCARDAMALIA, 1987) denotam, como já referimos, a presença de empreen- 
Uma Proposta de Modelo Metacognitivo de Aquisição da Escrita no Ensino Universitário... Nelson Maurício Ernesto

dimentos cognitivos que auxiliam os mecanismos de escrita, sobretudo porque se apoiam na teoria sobre o processamento da informação pelo indivíduo. Com efeito, um modelo anterior e considerado pioneiro do processo de produção escrita (ROHMAN, 1965) já destacava a presença da cognição na produção escrita, porque clamava existir uma constante autorregulação deste processo. Contudo, esse modelo mostrou-se ineficaz por considerar que as fases do processo de produção escrita ocorrem de forma sucessiva, o que foi negado pelos modelos subsequentes (SOMMERS, 1979 citado por KELLOGG, 1988 HAYES; FLOWERS, 1980).

No modelo proposto por Hayes e Flowers (1980), marcadamente cognitivo, defende-se que a produção escrita envolve, além do processo de produção escrita, (i) o contexto da tarefa, (ii) a memória de longo-prazo. Em (i), o contexto da tarefa há, essencialmente, questões relativas à produção, à estruturação e evolução do texto, aos instrumentos de escrita e às fontes de informação exógenas manipuladas no decurso da produção escrita (dicionários, manuais). Já em (ii), a memória de longo-prazo congrega saberes relativos ao tópico de escrita, a audiência do produto da escrita, suas possíveis expectativas e tipologia textual a ser adotada. A questão central nesse modelo consiste em considerar que 0 produtor de escrita reage, frequentemente, aos seus produtos de escrita, levando-o a estabelecer, no decurso da produção textual, a uma reanálise dos objetivos do texto.

O modelo proposto por Bereiter e Scardamalia (1987) também assenta em princípios cognitivos e, nessa sequência, é avançada a diferença entre dois submodelos referentes à explicitação do conhecimento e transformação do conhecimento que correspondem, respetivamente, a formas de produção textual de produtores principiantes de escrita e às dos produtores avançados de escrita. Considera-se, por conseguinte, que o primeiro submodelo resulta de um plano e texto que, essencialmente, é uma listagem de conteúdos, o que caracteriza os produtores principiantes de escrita, posto que estes, no geral, traduzem para o texto o que sabem a respeito de um determinado tópico de escrita. Por oposição, exis- 
Uma Proposta de Modelo Metacognitivo de Aquisição da Escrita no Ensino Universitário... Nelson Maurício Ernesto

te o submodelo da transformação do conhecimento revelado pelo produtor avançado de escrita, em que há um esforço cognitivo que se traduz no desenvolvimento de estratégias metacognitivas que incidem sobre o processo de escrita, a audiência e os problemas de escrita.

Assim sendo, na produção escrita realizada pelo produtor avançado de escrita, ocorrem estratégias metacognitivas de monitorização e autorregulação do processo de escrita, o que não é verificável na produção escrita de produtores principiantes de escrita que, como mencionámos, é caracterizada pela explicitação do conhecimento.

Como referimos, no modelo de Hayes e Flowers (1980), são avançadas as fases do processo de escrita e, como há um consenso entre os investigadores (GRAHAM; HARRIS, 2000 ZIMMERMAN RISEMBERG, 1997 PIRES, 2015) em considerar que essas fases do processo de escrita são as mais recorrentes para explicitar a processualização da produção escrita, em seguida, procedemos a uma descrição das fases do processo de escrita.

\section{Fases do processo de produção da escrita}

As fases de processo de produção escrita, propostas por Hayes e Flowers (1980), consistem de uma reformação das fases de processo de produção escrita primeiramente cunhadas por Rohman (1965). Esse modelo, que incluía a autorregulação da produção escrita em cada fase do seu processo, defendia que o processo de produção escrita ocorria em 3 fases sucessivas: (i) pré-escrita, em que se estabelecem os planos de escrita; (ii) escrita, em que se transcrevem em texto escrito os planos de escrita anteriormente estabelecidos; (iii) reescrita, que consiste na revisão do texto e sua edição. Como anteriormente referimos, esse modelo mostrou-se ineficaz porque considera que o processo de produção escrita é sequenciado e não recursivo, ou seja, o modelo não tem em conta que existe uma interatividade entre os 3 processos de escrita. 
Uma Proposta de Modelo Metacognitivo de Aquisição da Escrita no Ensino Universitário... Nelson Maurício Ernesto

Nesse contexto, Hayes e Flowers (1980), assumindo que nas etapas de produção escrita existe uma confluência de fases na elaboração do texto num determinado estágio do processo, propõem no seu modelo que nesse processo ocorre, com a planificação, a textualização e a revisão do texto.

Como vimos, esse modelo assenta na teoria psicológica de processamento de informação e assume que em cada fase do processo de produção escrita são desencadeados empreendimentos cognitivos de monitorização e autorregulação da cognição. Nessa base, analisaremos cada uma das fases do processo de produção escrita, procurando incidir sobre as habilidades cognitivas desenvolvidas nessas fases do processo de produção escrita.

\subsection{Planificação}

Na planificação, é produzido um primeiro texto que resulta do agrupamento de informações recolhidas e a estruturação dessa informação com vista à redação do texto, o que corresponde à macroplanificação e à microplanificação, respetivamente.

Com efeito, na macroplanificação, verifica-se a recolha de informações básicas para a produção textual (bibliotecas ou outros locais de pesquisa do tópico de escrita) e, por outro lado, opera-se a criação e organização de ideias e a delimitação de objetivos a atingir com a redação do texto que, certamente, devem ter como foco a audiência ou o destinatário do texto. Por sua vez, a microplanificação procura estabelecer uma ordenação esquemática das ideias ou conteúdos recolhidos sob forma de texto, fazendo intervir (i) o contexto da tarefa - as questões relativas à produção, a estruturação e evolução do texto, os instrumentos de escrita e as fontes de informação exógenas manipuladas no decurso da produção escrita (dicionários, manuais); (ii) a memória de longo-prazo - congrega saberes relativos ao tópico de escrita, a audiência do produto da escrita e suas possíveis expectativas e tipologia textual a ser adotada (SITKO, 1998 AMOR, 2001). 
Uma Proposta de Modelo Metacognitivo de Aquisição da Escrita no Ensino Universitário... Nelson Maurício Ernesto

Essas ações podem ser traduzidas em termos cognitivos. Considera-se, por conseguinte, que a planificação envolve 3 subprocessos cognitivos: seleção de dados a incluir no texto, delimitação de objetivos para a redação do texto e, finalmente, reordenação na memória de longo-prazo da informação recolhida, posto que ela será necessária para a redação do texto (SITKO, 1998).

Enfim, a planificação envolve a construção de um primeiro texto que invoca a macroplanificação, o conjunto de ideias isoladas; bem como a microplanificação, organização das ideias recolhidas com vista à produção do texto. Por conseguinte, em termos cognitivos, são desenvolvidas três estratégias de monitorização e autorregulação da cognição como seleção de dados a incluir no texto, delimitação de objetivos para a redação do texto e, por fim, reordenação na memória da informação recolhida.

\subsection{Textualização}

$\mathrm{Na}$ textualização, traduz-se em texto escrito os planos de escrita anteriormente estabelecidos ao nível da planificação, ou seja, opera-se a adequação das ideias e objetivos fixados na planificação em texto escrito, o que envolve a seleção lexical e construção frásica.

Nessa fase do processo de produção escrita, procura-se fazer uso de estratégia de enunciação linguística e pragmática através da construção de frases que concordam com a norma linguística prevalecente e da identificação de conjunções ou locuções conjuntivas que permitam a ligação entre as frases, dando-se coesão ao texto. Considera-se que, ao desenvolver estas ações, o produtor de escrita está a desenvolver estratégias retóricas.

No desenvolvimento dessas ações (estratégias de retórica), deve-se procurar evitar grafar no texto termos que suscitem a incompreensão da mensagem a comunicar. Esse posicionamento mostra que a fase de textualização não é sequencial, ou seja, há sempre recuos e avanços na redação do texto, na tentativa de 
Uma Proposta de Modelo Metacognitivo de Aquisição da Escrita no Ensino Universitário... Nelson Maurício Ernesto

orientá-lo no sentido de cobrir os objetivos anteriormente definidos na planificação.

Em termos cognitivos, defende-se que o produtor de escrita desenvolve estratégias de monitorização e autorregulação (o controle da cognição no decurso da produção escrita) que podem compreender a enunciação linguístico-pragmática, o que também inclui o isolamento de melhores marcadores discursivos que facilitem a coesão textual ou a escolha da palavra que melhor elucida o sentido da mensagem a transmitir (ZIMMERMAN; RISEMBERG, 1997 SITKO, 1998).

Sumariando, na textualização ocorre a tradução das ideias e esquemas que foram reunidas na fase da planificação em texto escrito. Desenvolvem-se, por isso, estratégias retóricas que se resumem, essencialmente, na construção do enunciado linguística e semanticamente orientados. As estratégias de monitorização e autorregulação estão relacionadas com a procura de elementos discursivos que, de forma mais acertada, traduzem o sentido que se pretende transmitir no texto.

\subsection{Revisão}

Nessa fase do processo de produção escrita, o produtor de escrita reanalisa o produto escrito e o relaciona com a sua ideia interiorizada de texto pretendido. Assim sendo, na revisão, procura-se elevar a qualidade do texto redigido na textualização através de dois subprocessos básicos: releitura do texto e correção do texto (edição) (HAYES; FLOWER, 1980).

Com efeito, o que o produtor da escrita faz é uma releitura (avaliação) do texto em termos de correspondência com os objetivos fixados, operando a correção dos erros eventualmente surgidos (edição). Essa correção de erros (edição) pode corresponder a uma tentativa de enquadrar o que foi escrito à norma linguística vigente, o que necessariamente conduz a uma verificação, entre outros aspetos, da adequação do texto às regras ortográficas 
Uma Proposta de Modelo Metacognitivo de Aquisição da Escrita no Ensino Universitário... Nelson Maurício Ernesto

aceitas pela comunidade linguística. Nessa perspetiva, defende-se que na correção de erros seguem-se três etapas, nomeadamente o isolamento do erro, descrição da sua característica e, finalmente, sua correção (FLOWER, 1989; BARBEIRO, 1990).

Esse procedimento de correção de erros (edição), que, na verdade, consiste numa reescrita do texto, pode ser feito com o apoio de fichas ou uma listagem de elementos controladores (ficha de erros de escrita, uso de gramáticas, dicionários ou prontuários) que conduzam a uma correção mais eficaz do produto de escrita (AMOR, 2001).

Considera-se que essas duas ações do processo de revisão (releitura e edição do texto) concorrem para desencadear ações metacognitivas. Ou seja, o produtor de escrita, ao estabelecer uma confrontação entre o texto produzido e um texto paradigma desejado, ou ainda, ao avançar para o isolamento de erros do produto de escrita, o que, necessariamente, conduz a uma reescrita e reestruturação do texto, faz intervir empreendimentos cognitivos de monitorização e autorregulação da cognição nas ações desta fase do processo de escrita (ZIMMERMAN; RISEMBERG, 1997 SITKO, 1998).

\section{Ensino metacognitivo de produção escrita em Língua Segunda (LS)}

O processo de produção escrita, enquanto metodologia de ensino, trouxe contribuições ao nível do ensino da produção escrita que perduram há mais de 15 anos, retirando do domínio do ensino as metodologias tradicionais de ensino da produção escrita, tais como a composição controlada e abordagem da composição retórica (KRAPELS, 1990) que, entretanto, entraram em desuso (GRABE; KAPLAN, 1996).

Apesar da metodologia do ensino da produção escrita centrada sobre o processo de escrita ter revolucionado o ensino da pro- 
Uma Proposta de Modelo Metacognitivo de Aquisição da Escrita no Ensino Universitário... Nelson Maurício Ernesto

dução escrita, defende-se que o ensino dela, que se ocupa apenas de explicitar as fases do processo de escrita, não parece conduzir os estudantes a um melhor desempenho em termos de elaboração do texto.

Grabe e Kaplan (1996, p. 316) sustentam esse postulado afirmando que "há relativamente pouca evidência empírica de que o processo de escrita em si leva a uma escrita significativamente meIhor ou que está sendo realizada de forma eficaz, mesmo em aulas rotuladas como sendo orientadas para o processo de escrita". Ou seja, a mera clarificação e explicitação das etapas do processo de produção não parecem ser suficientes para garantir que os alunos serão bons produtores de escrita.

À luz da teoria da metacognição, em que se relaciona o pensar e a escrita, tem-se defendido que o treino de estratégias de aprendizagem ligadas à produção escrita conduz a uma produção mais eficiente. De um modo geral, considera-se que esse treino pode ser feito mediante a explicitação do modelo de uso das estratégias de aprendizagem em que o professor as ensina e os pupilos colaboram através de perguntas que colocam ao professor. Por outro lado, o modelo pode partir dos próprios discentes que, ao produzirem o texto, verbalizam as estratégias que usam, enquanto o professor reduz a sua ação porque apenas os estimula a procurarem estratégias de aprendizagens que melhor ajudam a compor o texto (GRABE; KAPLAN, 1996).

Note-se, entretanto, que o corpo teórico sobre o ensino de estratégias de aprendizagem em LS teve a sua gênese a partir da preocupação de descrever os elementos constitutivos de indivíduos produtivos em LS. Essas pesquisas estavam, por consequência, centradas sobre o "bom aprendente da língua" (NAIMAN et al., 1978 RUBIN, 1975) e tomaram como base relatos de estratégias de aprendizagem usadas pelos discentes e/ou estratégias de aprendizagem reveladas na aprendizagem de LS. Essas pesquisas concluíram que, de um modo geral, esses aprendentes usam estratégias de aprendizagem no decurso da aprendizagem de uma LS e, por outro lado, é possível isolar, construir uma tipologia e explicitar 
Uma Proposta de Modelo Metacognitivo de Aquisição da Escrita no Ensino Universitário... Nelson Maurício Ernesto

as estratégias de aprendizagem a estudantes com dificuldades de aprendizagem de LS (O'MALLEY; CHAMOT, 1990).

No centro das abordagens de ensino das estratégias de aprendizagem ligadas à produção estão as etapas do processo de produção escrita, posto que são invocadas estratégias de aprendizagem diretamente relacionadas com o processo de produção escrita, nomeadamente estratégias de planificação, estratégias de textualização, estratégias de revisão e estratégias de edição (GRABE; KAPLAN, 1996; SITKO, 1998). Essa posição decorre do fato de este tipo de ensino poder propiciar habilidades cognitivas de reflexão da aprendizagem em que se encontram envolvidos os respetivos estudantes, isto é, o processo de produção escrita.

Sitko $(1998$, p. 99) parece sustentar as asserções anteriormente descritas neste artigo, pois considera que "intervenções educacionais e redação de currículos devem ser projetadas para sugerir o uso de estratégia apropriada relacionada a planificação, textualização, revisão e edição", e, por outro lado, que "deve ficar evidente que os próprios produtores de escrita desenvolvem por si conhecimento metacognitivo e estratégia para planificação, organização, textualização, revisão e edição. A instrução das estratégias de produção escrita é considerada metacognitiva apenas quando envolve ativamente os alunos na compreensão de sua própria aprendizagem" (SITKO, 1998, p. 100).

Ou seja, um programa de ensino de estratégias de aprendizagem associadas à produção escrita, deve procurar desenvolver estratégias metacognitivas ao nível das fases do processo de escrita, o que permite que os próprios alunos reflitam sobre o processo de aprendizagem que acedem. Uma aprendizagem metacognitiva da produção escrita só é efetiva se os alunos estão conscientes do processo em que estão envolvidos. 


\subsection{Modelo metacognitivo de ensino de produção escrita em LS}

Em LS, o modelo metacognitivo de ensino de estratégias de aprendizagens ligadas à produção escrita parece inscrever-se nos modelos usuais de treino de estratégias de aprendizagem em LS, porque estes abarcam as 4 modalidades da língua, que, obviamente, incluem a escrita (OXFORD, 1990 O'MALLEY; CHAMOT, 1990 CHAMOT et al., 1999). No presente artigo, recorremos a Chamot; O'Malley (1994) e Chamot et al. (1999) para uma descrição geral sobre o funcionamento do modelo de ensino de estratégias cognitivas a estudantes de LS, porque o modelo apresentado por esses autores tem sido, de um modo geral, referenciado como paradigmático sobre o ensino de estratégias de aprendizagem em LS (MC DONOUGH, 1995, COHEN, 1998 MACARO, 2006). No entanto, porque existe um paralelismo entre o modelo apresentado por estes autores e o descrito por Anderson (2002), procederemos também a uma descrição do modelo apresentado por este último autor.

O modelo apresentado por Chamot; O'Malley (1994) Chamot et al. (1999) foi construído a partir de um corpus de estratégias de aprendizagem usadas por sujeitos aprendendo uma LS, desde os níveis mais elementares de aprendizagem ao ensino universitário. Consequentemente, a inclusão das diferentes estratégias de aprendizagem no modelo é justificada pela sua validade anteriormente verificada em situações de aprendizagem de LS. Assumindo que existe um carácter interativo entre as etapas do seu modelo, esses autores sustentam que as etapas do modelo metacognitivo de ensino de estratégias de aprendizagem em LS assentam no seguinte: (i) planificação, (ii) monitorização, (iii) resolução do problema e (iv) avaliação.

Na planificação, o professor propõe aos estudantes a matéria linguística a ser analisada em aula, explicando o seu princípio orientador. Em seguida, o professor estimula-os a planificarem a sua aprendizagem e identificar as estratégias de aprendizagem 
Uma Proposta de Modelo Metacognitivo de Aquisição da Escrita no Ensino Universitário... Nelson Maurício Ernesto

que lhes facultarão uma melhor aprendizagem do material de língua especificado. Para atender a essa orientação do professor, os estudantes podem definir os seus próprios objetivos para aprendizagem do conteúdo linguístico em causa, procurarem invocar conhecimentos anteriores respeitantes ao item linguístico em análise e prever possíveis dificuldades na aprendizagem do mesmo.

Na monitorização, o professor conduz os seus pupilos a monitorar o seu desempenho na aprendizagem da informação linguística, através da verificação da utilidade da estratégia de aprendizagem na compreensão de tal matéria em análise. Os estudantes deverão, entre outras ações, autoquestionar-se sobre a compreensão do fenômeno de língua e sobre as partes relativas a ele em aprendizagem que devem prestar mais atenção. Ou seja, os alunos deverão operar uma avaliação da eficácia e produtividade em termos de aquisição linguística das estratégias de aprendizagens eleitas para análise do conteúdo linguístico pré-definido.

Na etapa da resolução de problema, o professor guia os seus discentes a avançarem com soluções assim que eles se depararem com dificuldades no uso da estratégia de aprendizagem. Ou seja, o professor clarifica que a aplicação de uma determinada estratégia de aprendizagem pode não se mostrar eficaz para o tratamento do item linguístico em análise e, uma vez detetada ineficácia da estratégia de aprendizagem selecionada, deve-se ativar outra estratégia de aprendizagem que produza efeitos positivos na aquisição do mesmo aspeto linguístico definido. Assim sendo, os estudantes devem procurar ativar outras estratégias de aprendizagem logo que verificar que a aprendizagem não está a ocorrer com o uso da estratégia de aprendizagem selecionada, o que inclui o uso de recursos didáticos disponíveis e autorizados pelo professor.

Na etapa da avaliação, o professor estimula os alunos a refletir a respeito da sua aprendizagem, por meio da avaliação do grau de eficácia das estratégias de aprendizagem manipuladas na aquisição do conteúdo linguístico. Nesse sentido, os estudantes verificam se as estratégias aplicadas para a aprendizagem do item linguístico tiveram os efeitos desejados e, por outro lado, procu- 
Uma Proposta de Modelo Metacognitivo de Aquisição da Escrita no Ensino Universitário... Nelson Maurício Ernesto

ram verificar a forma de transferir a aplicabilidade da estratégia usada em outras situações de aprendizagem de itens linguísticos.

Na visão de Anderson (2002), o ponto central da metacognição ao nível da aprendizagem de LS está na capacidade do aprendente de avaliar a eficácia e produtividade do uso dessas estratégias e da aprendizagem, assim como ter a noção da transferibilidade das estratégias de aprendizagens usadas. Esse pesquisador apresentou um modelo de treino de estratégias de aprendizagens que tende a ter um paralelismo com o modelo apresentado por Chamot; O'Malley (1994) e Chamot et al. (1999).

No seu texto, Anderson (2002) propõe como estratégia de avaliação dessas estratégias bem como da aprendizagem a resposta a 4 perguntas que ligam ao modelo que sugere: $O$ que é que pretendo atingir? Que estratégias de aprendizagens é que estou a usar? Qual é o efeito das estratégias de aprendizagens na aprendizagem? Como é que posso melhorar o meu desempenho?

Na perspetiva deste investigador, o professor - ao aplicar aos seus estudantes uma ficha em que incluam, na generalidade, este conjunto de perguntas - pode preencher os requisitos da avaliação destas estratégias e da aprendizagem, porque no desenvolvimento desta tarefa os pupilos relembram o item linguístico, as estratégias de aprendizagens invocadas em aula, avaliando, desse modo, a sua aprendizagem.

\section{Conclusão}

A metacognição é um ramo científico da Psicologia Cognitiva e foi inicialmente proposta por John Flavell, nos anos 70, que a conceitualizou como a cognição da cognição. Nesse contexto, defende-se, por um lado, que qualquer conceito de metacognição que surja na literatura científica deve refletir o sentido original de metacognição proposto por John Flavell. Por outro lado, sustenta-se que a metacognição é um aspeto intrínseco à cognição e, por 
Uma Proposta de Modelo Metacognitivo de Aquisição da Escrita no Ensino Universitário... Nelson Maurício Ernesto

isso, não parece haver uma diferença em termos de níveis (alto e baixo) entre a metacognição e cognição.

A produção escrita, em que a ortografia e acentuação são elementos integrantes, é determinada por processos cognitivos que permitem a monitorização e autorregulação das fases do processo de produção escrita, nomeadamente planificação, textualização, revisão e edição. Nessa base, defende-se que se houver produtores de escrita pouco eficientes (por exemplo, na ortografia e acentuação), pode-se propor uma metodologia de treino de estratégias de aprendizagem (metacognitivas) diretamente relacionadas com as fases do processo de produção escrita. Essa abordagem metodológica deve ser eleita pelo professor de português, porque a que propõe a mera explicitação das fases do processo de escrita não se mostra muito produtiva quando se pretende possibilitar uma maior eficácia a produtores ineficientes de escrita.

Nessa ordem de ideias, defendeu-se que, para o treino de estratégias de aprendizagem ligadas ao processo de escrita, pode-se recorrer a um modelo de explicitação de estratégias de aprendizagens que, por se centrar sobre as 4 modalidades da língua, faz alusão à escrita. $O$ modelo de treino de estratégias de aprendizagens baseado na resolução de problemas envolvendo 4 etapas, nomeadamente planificação, monitorização, resolução do problema e avaliação, parece servir a esse objetivo de treinar estrategicamente os alunos com dificuldades de aprendizagem de escrita na LS. No entanto, considera-se que, além de levar os alunos a revelar as suas estratégias de aprendizagem na aquisição da produção escrita e em outras situações de realização dessa atividade, o professor deve conduzir os alunos a avaliar a validade das estratégias de aprendizagem usadas, assim como da aprendizagem em si, mediante uma ficha de avaliação que aluda a estes dois aspetos.

\section{Referências}

AMOR, E. Didáctica do Português - Fundamentos e Metodologias. $2^{\mathrm{a}}$ edição. Lisboa: Texto Editora, 2001. 
Uma Proposta de Modelo Metacognitivo de Aquisição da Escrita no Ensino Universitário... Nelson Maurício Ernesto

ANDERSON, N. The Role of Metacognition in Second Language Teaching and Learning. Disponível em: www.cal.org/resources/digest/0110anderson.html. Acesso: 22.set.2020, 2002.

BAKER, L.; BROWN, A. L. Metacognitive Skills and Reading. In: PEARSON, P. D.; BARR, R.; KAMIL M. L.; MOSENTHAL, P. (Eds.). Handbook of Reading Research. New York: Longman, 1984, p. 353 - 394.

BARBEIRO, L. F. O processo de escrita e o computador. Revista portuguesa de educação, Lisboa, v. 3, n. 3, 1990, p. 139-149.

BEREITER, C.; SCARDAMALIA, M. The psychology of written composition. Hillsdale, NJ: Erlbaum, 1987.

BROWN, A. Metacognitive, Executive Control, Self-Regulation, and Other Mysterious Mechanisms. In: WEINER, F.; KLUWE, R. (Eds.). Metacognition, Motivation and Understanding. New Jersey: Lawrence Erlbaum Associates, 1987, p. 65-116.

CHAMOT, A. U.; BARNHARDT, S.; EL-DINARY, P. B.; ROBBINS, J. The Learning Strategies Handbook. New York: Longman, 1999.

COHEN, A. D. Strategies in learning and using a second language. Harlow: Longman, 1998.

CROSS, D. R.; PARIS, S. G. Development and Instructional Analyses of Children's Metacognition and Reading Comprehension. Journal of Educational Psychology, n. 80, 1988, p. 131-142.

ERNESTO, N. Ensino de Estratégias Metacognitivas a Estudantes Universitários Moçambicanos com Dificuldades na Produção Escrita. 2006. 120f. Dissertação (Mestrado em Ensino do Português Língua Segunda e Estrangeira) - Faculdade de Ciências Socias e Humana, Universidade Nova de Lisboa, Lisboa, 2006.

FLAVELL, J. Metacognition and Cognitive Monitoring: A New Area of Cognitive-Development Inquiry". In: NELSON, T. O. (Ed.). Metacognition: Core Readings. Boston: Allyn and Bacon, 1979, p. 3-7. FLAVELL, J. Metacognitive Aspects of Problem Solving. In: RESNICK, L. (Ed.). The Nature of Inteligence. New Jersey: Lawrence Erlbaum Associates, 1976, p. 231-235. 
Uma Proposta de Modelo Metacognitivo de Aquisição da Escrita no Ensino Universitário... Nelson Maurício Ernesto

FLOWER, L. Problem-Solving Strategies for Writing. $3^{\text {a }}$ edição.

Marrickville: Harcourt Publishers Group, 1989.

FLOWER, L.; HAYES, J. R. The dynamics of composing: Making plans and juggling constraints. In: GREGG, L.; STEINBERG, E. (Eds.). Cognitive processes in writing, 1980, p. 31-50.

GONÇALVES, P.; VICENTE, F. Erros de Ortografia no Ensino Superior. In: GONÇALVES P. (Org.). O Português escrito por estudantes universitários: Descrições linguísticas e estratégias didácticas. Maputo: Texto Editores, 2010, p. 51 - 72.

GONÇALVES, P.; VICENTE, F. Perfil linguístico dos alunos da 10ª classe: Erros ortográficos e de acentuação - Projecto Introdução da disciplina de Português nos Institutos do Magistério Primário. Maputo: Instituto Nacional do Desenvolvimento da Educação, Programa de Apoio ao Sector da Educação (PASE), Moçambique-Finlândia (não publicado), 2005.

GRABE, W.; KAPLAN, R. B. Theory and Practice of Writing: An Applied Linguistic Perspective. New York: Longman, 1996.

GRAHAM, S.; HARRIS, K. R. The Role of Self-Regulation and Transcription Skills in Writing and Writing Development. Educational Psychologist, EUA, v. 35, n.1, 2000, p. 3-12.

HAYES, J. R.; FLOWER, L. Identifying the Organization of Writing Processes. In: GREGG, L. W.; STEINBERG, E. R. (Eds.). Cognitive Processes in Writing: An Interdisciplinary Approach. Hillsdale, NJ: Lawrence Erlbaum, 1980, p. 3-30.

HORTA, I.; ALVES, M. Desenvolvimento e aprendizagem da ortografia: Implicações educacionais. Análise Psicológica, Lisboa, n.1, v. 22, 2004, p. 213-223.

KARMILOFF-SMITH, A. Learning, development, and conceptual change. Beyond modularity: A developmental perspective on cognitive science. Massachusetts: MIT Press, 1992.

KELLOGG, R. T. Attentional overload and writing performance: Effects of rough draft and outline strategies. Journal of Experimental 
Uma Proposta de Modelo Metacognitivo de Aquisição da Escrita no Ensino Universitário... Nelson Maurício Ernesto

Psychology: Learning, Memory, and Cognition, EUA, v. 14, n. 2, 1988, p. 355-365.

KRAPELS, A. An overview of second language writing process research. In: KROLL, B. (Ed.). Second language writing: Research insights for the classroom. New York: Cambridge University Press, 1990, p. 37-56.

MACARO, E. Strategies for language learning and for language use: Revising the theoretical framework. Modern Language Journal, EUA, n. 90, 2006, p. 320-337.

MCDONOUGH, S. H. Strategy and skill in learning a foreign language. London: Edward Arnold, 1995.

MORAIS, A. G.; TEBEROSKY, A. Erros e transgressões infantis na ortografia do português. Discursos, Lisboa, n. 8, 1994, p. 15-51.

NAIMAN, N.; FROHLICH, M.; STERN, H. H.; TODESCO, A. The good language learner. Ontario: The Ontario Institute for Studies in Education, 1978.

O'MALLEY, J. M.; CHAMOT, A. U. Learning strategies in second language acquisition. Cambridge: CUP, 1990.

OXFORD, R. Language learning strategies: what every teacher should know. New York: New Bury House Publishers, 1990.

\section{PIRES, A. A produção textual escrita de alunos do ensino médio} egressos do programa de correção de fluxo: um estudo sobre letramento escolar. 2015. 136f. Dissertação (Mestrado em Linguística) Universidade Federal de Santa Catarina, SC, 2015.

REBELO, J. A. S.; FONSECA, A. C. Aprendizagem da escrita elementar em português e suas dificuldades: um estudo longitudinal. Revista Portuguesa de Pedagogia, v. 35, n 2, 2001, p.33-63.

ROHMAN, D. G. Pre-writing the stage of discovery in the writing process. College Composition and Communication, EUA, v.16, n. 2, 1965, p. 106-112.

RUBIN, J. What the 'good language learner' can teach us. TESOL

Quarterly, EUA, n. 9, 1975, p. 41-51. 
Uma Proposta de Modelo Metacognitivo de Aquisição da Escrita no Ensino Universitário... Nelson Maurício Ernesto

SIOPA, C. Aperfeiçoar a escrita em Português na Universidade em Moçambique. Revista Científica da Universidade Eduardo Mondlane, Maputo, v. 1, n. 1, 2015, p. 52-66. Disponível em: Downloads/Siopa_aperfeioar_a_escrita_Moambique.pdf. Acesso: 22.set.2020.

SIOPA, C.; ERNESTO, N.; COMPANHIA, C. A competência em português dos estudantes universitários: primeira abordagem. Revista Idiomático, Lisboa, 2003, p. 1-20. Disponível: http://cvc.instituto-camoes.pt/idiomatico/01/competencia_em_portugues.pdf. Acesso: 22.set. 2020.

SITKO, B. M. Knowing how to write: Metacognition and writing instruction. In HACKER, D. J.; DUNLOSKY, J.; GRAESSER A. C. (Eds.). The educational psychology series. Metacognition in educational theory and practice, EUA, 1998, p. 93-115.

ZIMMERMAN, B. J.; RISEMBERG, R. Becoming a self-regulated writer: A social cognitive perspective. Contemporary Educational Psychology, EUA, v. 22, n. 1, 1997, p. 73-101. 